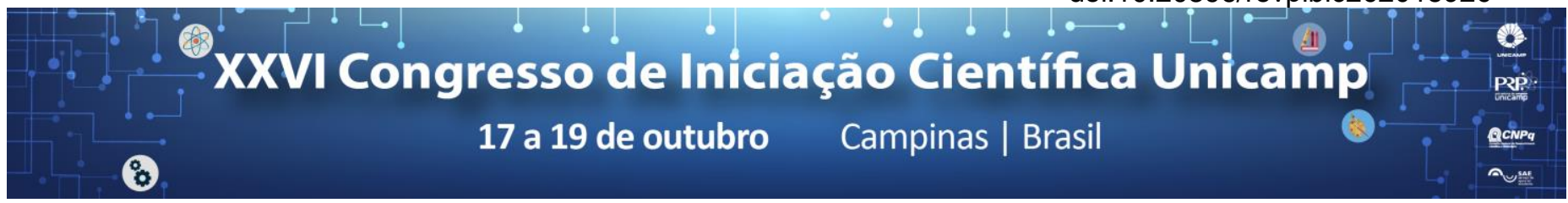

\title{
Cost-effectiveness analysis of influenza A (H1N1) chemoprophylaxis in Unified Health System in Brazil
}

\section{Luisa Vecoso*, Marcus Silva, Everton Silva, Mariangela Rezende, Tais Galvao}

\begin{abstract}
BACKGROUND: Oseltamivir and zanamivir have indication for treating symptomatic flu and in prophylaxis in epidemics for groups with high risk of complications. METHODS: Effectiveness data was identified in literature review, and costs were obtained from official systems and micro-costing. RESULTS: We adopted a decision-tree model to assess the effectiveness of chemoprophylaxis in Brazilian Unified Health System (SUS) perspective with willingness to pay BRL 30,000.00/QALY. The incremental cost-effectiveness ratio for chemoprophylaxis compared to no prophylaxis was 2,921.14/QALY. CONCLUSION: Chemoprophylaxis is cost-effective in Brazilian scenario.
\end{abstract}

\section{Key words:}

Cost-effectiveness, influenza, Brazil.

\section{Introduction}

Oseltamivir and zanamivir are antiviral drugs recommended by World Health Organization (WHO) and Brazilian Health Ministry for chemoprophylaxis of influenza $A(\mathrm{H} 1 \mathrm{~N} 1)$ for high risk groups $(1,2)$.

The analysis of complete evidence identified the risk of bias in favor of the technology (3) and the costeffectiveness was assessed in different countries but no analysis in Brazilian context was available.

\section{Results and Discussion}

We identified the effectiveness data in literature review. We assessed costs for the payer perspective in disease period and obtained data from official Brazilian Ministry of Health system and micro-costing at Unicamp University Hospital (study approved by Unicamp ethics committee, report 2.357.158/2017). Cost and effectiveness data is shown in Table. We adopted a decision-tree model (Figure) and willingness to pay BRL 30,000.00/QALY (quality-adjusted life years). The incremental cost-effectiveness ratio (ICER) was calculated for prophylaxis compared to no prophylaxis. We tested the robustness of results using deterministic and probabilistic sensitivity analysis.

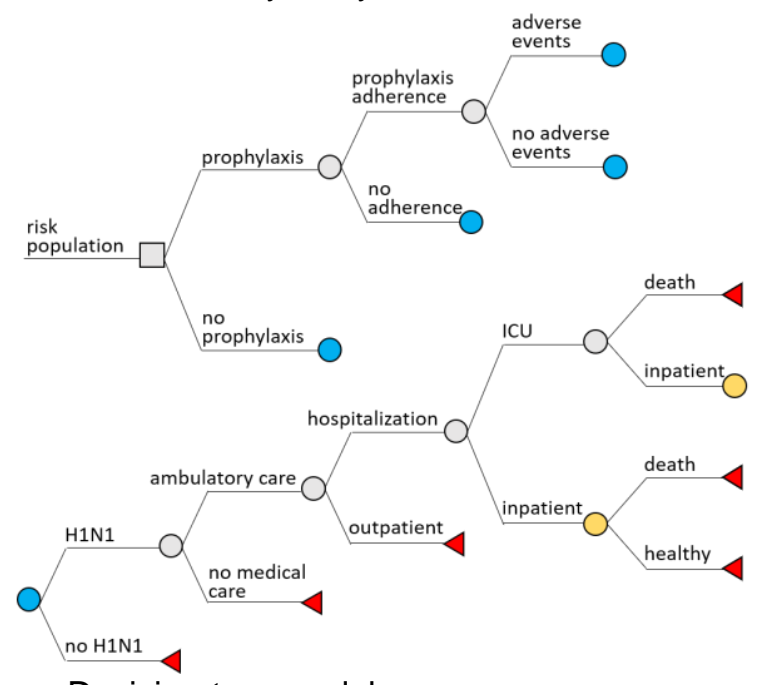

Figure. Decision-tree model

Calculated ICER as -2,921.14/QALY and -337.84 per $\mathrm{H} 1 \mathrm{~N} 1$ case avoided, with $43 \%$ probably of being of lower cost and higher effectiveness.
Table. Variables adopted in the model

\begin{tabular}{|l|l|}
\hline Model variables & Effectiveness $(\mathrm{Cl} 95 \%)$ \\
\hline Prophylaxis adherence & $0.70(0.54 ; 0.83)$ \\
\hline Adverse events & $0.09(0.02 ; 0.18)$ \\
\hline $\begin{array}{l}\text { Relative risk of H1N1 with } \\
\text { chemoprophylaxis }\end{array}$ & $0.43(0.33 ; 0.57)$ \\
\hline H1N1 in risk population & $0.14(0.11 ; 0.16)$ \\
\hline Ambulatory care & $0.67(0.58 ; 0.75)$ \\
\hline Hospitalization & $0.43(0.39 ; 0.42)$ \\
\hline Death in hospital & $0.14(0.12 ; 0 ; 15)$ \\
\hline Intensive care unit & $0.23(0.20 ; 0.27)$ \\
\hline Death in intensive care unit & $0.40(0.29 ; 0.52)$ \\
\hline Health states & Utility $(\mathrm{Cl} 95 \%)$ \\
\hline H1N1 & $0.50(0.46 ; 0.53)$ \\
\hline H1N1 with hospitalization & $0.23(0.18 ; 0.28)$ \\
\hline Adverse events & $-0.20(-0.29 ;-0 ; 05)$ \\
\hline Healthy & $0.89(0.88 ; 0.89)$ \\
\hline Cost & $\mathrm{BRL}(\mathrm{SD})$ \\
\hline Chemoprophylaxis & $39.42(17.94)$ \\
\hline Ambulatory care & $12.47(5.21)$ \\
\hline Hospitalization & $5,727.59(7,758.28)$ \\
\hline Intensive care unit & $19,217.25(7,917.33)$ \\
\hline Adverse events & $292.05(724.95)$ \\
\hline Notes: Cl, confidence intervar; BR & Brazian rear SD \\
\hline
\end{tabular}

Notes: Cl, confidence interval; BRL, Brazilian real; SD, standard deviation.

\section{Conclusions}

Influenza A (H1N1) chemoprophylaxis is cost-effective in SUS perspective.

\section{Acknowledgement}

The study was sponsored by HAOC - PROADI SUS.

(1) World Health Organization. Pharmacological Management of Pandemic Influenza A (H1N1) 2009. [Available from:

http://www.who.int/csr/resources/publications/swineflu/h1n1_use antivir als_20090820/en/.

(2) Brasil. Ministério da Saúde. Secretaria de Vigilância em Saúde. Departamento de Vigilância das Doenças Transmissíveis. Protocolo de tratamento de Influenza: 2015.

(3) Jefferson T, Jones MA, Doshi P, Del Mar CB, Hama R, Thompson MJ, et al. Neuraminidase inhibitors for preventing and treating influenza in healthy adults and children. Cochrane Database Syst Rev. 2014(4):Cd008965. 